\title{
Nasal and oral contribution to inhaled and exhaled nitric oxide: a study in tracheotomized patients
}

\author{
D.C.F. Törnberg*, H. Marteus", U. Schedin ${ }^{\Uparrow}$, K. Alving ${ }^{\#}$, J.O.N. Lundberg\#, E. Weitzberg*
}

\begin{abstract}
Nasal and oral contribution to inhaled and exhaled nitric oxide: a study in tracheotomized patients. D.C.F. Törnberg, H. Marteus, U. Schedin, K. Alving, J.O.N. Lundberg, E. Weitzberg. (C) ERS Journals Ltd 2002.

ABSTRACT: Nitric oxide (NO) is produced at different sites in the human airways and may have several physiological effects. Orally-produced NO seems to contribute to the levels found in exhaled air. Autoinhalation of nasal NO increases oxygenation and reduces pulmonary artery pressure in humans. The aim of this study was to measure the concentration and output of NO during nasal, oral and tracheal controlled exhalation and inhalation.
\end{abstract}

Ten tracheotomized patients and seven healthy subjects were studied. The mean \pm SEM fraction of exhaled NO from the nose, mouth and trachea was 56 $\pm 8,14 \pm 4$ and $6 \pm 1$ parts per billion (ppb), respectively. During single-breath nasal, oral and tracheal inhalation the fraction of inhaled NO was $64 \pm 14,11 \pm 3$ and $4 \pm 1$, respectively. There was a marked flow dependency on nasal NO output in the healthy subjects, which was four-fold greater at the higher flow rates, during inhalation when compared to exhalation.

There is a substantial contribution of nasal and oral nitric oxide during both inhalation and exhalation. Nasal nitric oxide output is markedly higher during inhalation, reaching levels similar to those that are found to have clinical effects in the trachea. These findings have implications for the measurement of nitric oxide in exhaled air and the physiological effects of autoinhaled endogenous nitric oxide.

Eur Respir J 2002; 19: 859-864.
*Dept of Anaesthesiology and Intensive Care, Karolinska Hospital, "Dept of Physiology and Pharmacology, Karolinska Institute, and "Dept of Anaesthesiology and Intensive Care, Danderyds Hospital, Stockholm, Sweden.

Correspondence: D.C.F. Törnberg, Dept of Anaesthesiology and Intensive Care, Karolinska Hospital, S-171 76 Stockholm, Sweden.

Fax: 468307795

E-mail: danieltornberg@hotmail.com

Keywords: Exhalation, expired, inhalation, pulmonary, respiration

Received: August 172001

Accepted after revision December 10 2001

The present study was supported by grants from the Swedish Medical Research Council $(12585,12586)$, the Swedish Heart Lung Foundation (41310), the AGA AB Medical Research Fund and the Karolinska Institute.
Nitric oxide (NO) was discovered in exhaled breath in 1991 by Gustafsson et al. [1]. This NO is probably produced from L-arginin by NO synthases (NOS) in the airways, since inhaled NOS inhibitors (i.e. $N(\mathrm{G})$ monomethyl-L-arginine) reduce airway excretion of NO [2, 3]. All three known isoforms of NOS, neuronal (nNOS), inducible (iNOS) and endothelial (eNOS), have been identified in human airway mucosa. In 1993, Alving et al. [4] reported elevated NO levels in the exhaled air of asthmatics and in 1994, KHARITONOV et al. [2] showed that exhaled NO was normalized when patients were treated with inhaled glucocorticoids. These findings triggered a rapidly growing interest in the measurement of exhaled NO. In healthy subjects, the major part of exhaled NO is produced within the upper airways and only a fraction of exhaled NO originates from the lower airways and lungs [4]. There is a high production of NO in the paranasal sinuses and the nasal cavity [3]. In four patients exhaling through their tracheostomy, the fraction of exhaled NO (FENO) was lower than both oral and nasal exhalation [5]. In addition, the oral cavity adds nonenzymatically-produced NO to the exhaled measurements. Facultative anaerobic bacteria in the oral mucosa reduce nitrate in the saliva to nitrite, which is further reduced to NO [6]. A standard procedure has recently been recommended by the American Thoracic Society (ATS) for the sampling of exhaled NO [7]. However, it is important to know to what extent the oral exhalation really originates from the lower airways and the lung.

Parallel to the discoveries of exhaled NO, it was shown in 1991 that, when inhaled, exogenous NO could reverse pulmonary hypertension by acting as a selective pulmonary vasodilator in animals at 5-80 parts per million (ppm) [8,9] and in humans at $40 \mathrm{ppm}$ [10]. Exogenous inhaled NO improved oxygenation in pulmonary hypertension of the newborn at $10 \mathrm{ppm}$ [11]. Moreover, in 1993, inhaled NO at 5-20 ppm proved to lower pulmonary artery pressure and increase arterial oxygenation in patients with acute respiratory distress syndrome (ARDS) [12]. In contrast to the relatively high levels of inhaled NO used in these studies, clinical effects have been shown using levels as low as 100-150 parts per billion (ppb) in acute respiratory failure and ARDS [13-15]. The level of NO in the nasal cavity varies with the measurement method [16] but often exceeds $100 \mathrm{ppb}$. Autoinhalation of nasal NO occurs and has physiological effects as an airborne messenger [3, 17]. Nasal 
breathing increases arterial oxygenation in healthy volunteers and reduces pulmonary arterial pressure in postoperative cardiac patients [18].

Tracheotomized patients were studied in order to quantify the contribution of NO from different sites of the respiratory tract. Thus, separation of the lower from the upper airways and fractionation of the NO by respective origin was possible.

\section{Materials and methods}

\section{Tracheotomized patients}

Ten patients attending the national centre for tracheotomized patients in Sweden at Danderyds Hospital were recruited after informed consent was obtained (table 1). The study was approved by the local ethics committee. Six of the cannulas had a cuff, which was inflated with saline or air according to what the patient was used to. Three of the patients had a silver cannula without an inflatable cuff. Even though these were individually shaped for each patient, some leakage around the cannula was expected. During tracheal breathing a nonfenestrated inner cannula was inserted and the cuff, if present, was inflated. When breathing through the upper airways, a fenestrated inner cannula was used and the cuff deflated.

NO measurements were made with a chemiluminescense technique during a vital-capacity exhalation single-breath manoeuvre. NO-free air was fed into a nondiffusing gas collection bag (Hans Rudolph, MO, USA). The bag was connected via a tube to a Y-piece, with two one-way valves, which was adapted to a mouthpiece, used for oral exhalation. A tight-fitting nasal mask (Respironics, Nantes, France) or a $0.5-\mathrm{m}$ tube adapted to the tracheostomy was used for nasal or tracheal exhalation, respectively. After inhalation, an immediate exhalation was performed with a target flow rate of $0.05 \mathrm{~L} \cdot \mathrm{s}^{-1}$ against a resistance of $200 \mathrm{cmH}_{2} \mathrm{O} \cdot \mathrm{L}^{-1} \cdot \mathrm{s}$ for $6 \mathrm{~s}$. The exhaled air passed through a one-way valve in the $\mathrm{Y}$-piece leading to a linear pneumotachymeter (Hans Rudolph), where flow and pressure were registered. A fraction of the exhaled air was sampled into the NO analyser (model 77 AM; Eco Physics, Dürnten, Switzerland), at a flow rate of $\sim 0.1 \mathrm{~L} \cdot \mathrm{min}^{-1}$, through a $1.1 \mathrm{~m}$ narrow-bore tube connected close to the mouthpiece. Signals from the pneumotachymeter and the NO analyser were sent to a computer for analysis by a specially-designed software program (Exhaled Breath Analyser; Aerocrine AB, Sweden). The recorded signals were visualized in real time on a computer screen, which acted as a guide to the subjects so that they could maintain a certain flow. The last $30 \%$ of the curves plotted on the screen were used for calculating values of fractional exhaled NO concentration (FENO,0.05) in ppb and flow $(Q)$ in $\mathrm{mL} \cdot \mathrm{s}^{-1}$. NO output $(V \mathrm{NO})$ was calculated as follows:

$$
V \text { NO }\left(\mathrm{nL} \cdot \min ^{-1}\right)=Q \times 0.06 \times \text { FENO }
$$

In the tracheotomized patients the ATS criteria for the sampling of exhaled NO were not fully met. The majority, but not all of the patients were able to reach within $10 \%$ of the target flow, $0.05 \mathrm{~L} \cdot \mathrm{s}^{-1}$. To reduce the patients' efforts they only made two exhalation measurements instead of three and mean values were used. Exhalations were made tracheally, orally, and nasally.

For inhalation sampling, a sterile suction catheter (Mülly, Maersk, Denmark) was introduced through a connector and placed $\sim 5 \mathrm{~mm}$ below the internal end of the cannula. The catheter was attached to the narrow-bore tube of the NO analyser. The pneumotachymeter was used for measuring inspiratory flow and was connected to the two-valve Y-piece described earlier. NO-free air was inhaled at a target flow of $0.2 \mathrm{~L} \cdot \mathrm{s}^{-1}$. This flow was chosen because the patients were unable to inhale and reach an NO plateau at $50 \mathrm{~mL} \cdot \mathrm{s}^{-1}$. NO concentration (fraction of inhaled NO (FINO,0.2)) in ppb and $Q$ were recorded during $3 \mathrm{~s}$. Inspiratory NO output was defined as follows:

$$
V \text { NO }\left(\mathrm{nL} \cdot \mathrm{min}^{-1}\right)=Q \times 0.06 \times \text { FINO,0.2 }
$$

For nasal inhalation, a nasal or oronasal mask was connected to the mouthpiece via a $0.5-\mathrm{m}$ tube. Oral inhalation was performed through the mouthpiece and a noseclip was used. For tracheal inhalation, the tracheal cannula was connected via the 0.5-m tube. Using the software, the NO curve was adjusted in time to compensate for the time lag caused by the volume of the tracheal catheter. NO values were measured from $0.3-0.9 \mathrm{~s}$ after the start of the NO signal. These values were used together with the flow values to calculate $V$ NO. Due to a technical error NO curves

\begin{tabular}{|c|c|c|c|c|c|c|}
\hline Patient no. & Age yrs & Sex & Cannula & Cuff & Disorder & Ventilator at night \\
\hline 1 & 65 & $\mathrm{M}$ & Silver & $\mathrm{N}$ & Scoliosis & $\mathrm{Y}$ \\
\hline 2 & 58 & $\mathrm{~F}$ & Silicon & $\mathrm{Y}$ & Post polio & $\mathrm{Y}$ \\
\hline 3 & 48 & $\mathrm{~F}$ & Silicon & $\mathrm{Y}$ & Post polio & $\mathrm{Y}$ \\
\hline 4 & 44 & $\mathrm{M}$ & Silver stent/Shiley & $\mathrm{Y}$ & Vocal cord palsy & $\mathrm{N}$ \\
\hline 5 & 60 & M & Shiley & $\mathrm{Y}$ & Post stroke & Y \\
\hline 6 & 66 & $\mathrm{~F}$ & Silver & $\mathrm{N}$ & Post polio & $\mathrm{Y}+\mathrm{O}_{2}$ \\
\hline 7 & 54 & $\mathrm{~F}$ & Silicone & $\mathrm{Y}$ & Scoliosis & $\mathrm{Y}$ \\
\hline 8 & 66 & $\mathrm{~F}$ & Silver & $\mathrm{N}$ & Scoliosis & $\mathrm{Y}$ \\
\hline 9 & 24 & $\mathrm{M}$ & Shiley & $\mathrm{Y}$ & Post encephalitis & $\mathrm{Y}$ \\
\hline 10 & 67 & $\mathrm{M}$ & Shiley & $\mathrm{Y}$ & Post polio & $\mathrm{Y}$ \\
\hline
\end{tabular}

Table 1.-Characteristics of 10 tracheotomized patients participating in the study

$\mathrm{O}_{2}$ : daytime oxygen requirement; $\mathrm{M}$ : male; F: female; N: no; Y: yes. 
were only recorded for the last six patients and only those data are used.

During tidal breathing, without flow measurements or resistance, peak levels of NO were recorded from the catheter placed in the trachea. One investigator continuously registered peak levels during $30 \mathrm{~s}$ of breathing. A mean value was calculated.

\section{Healthy subjects}

Healthy volunteers (aged 27-45 yrs, one female, six males) were studied. For measurements of inhaled $\mathrm{NO}$, a sterile suction catheter was inserted through one nostril until a gag reflex was experienced (range $8-11 \mathrm{~cm}$ from the nares). Plateau levels of NO were measured at the end of a 6-s constant-flow inhalation. The contralateral nostril was blocked with a cuffed catheter (Silkomed, Willy Rüsch AG, Germany). Measurements were made when inhaling NO-free air nasally (after nasal exhalation) through a tight-fitting oronasal mask. Exhaled NO was measured during plateau levels at the end of a 10-s single breath with a tight fitting oronasal mask and the same nostril blocked. A resistance of $50 \mathrm{cmH}_{2} \mathrm{O} \cdot \mathrm{L}^{-1} \cdot \mathrm{s}$ was required for the subject to control the flow rate. Flow and NO levels were recorded. The order in which the recordings were made was changed between the subjects. Two measurements on target flows $0.05,0.1,0.2$ and $0.3 \mathrm{~L} \cdot \mathrm{s}^{-1}$ gave mean values for NO concentration and output. On another day after nasal end-expiration plus $0,1,2$ and $3 \mathrm{~s}$, a bolus of $25 \mathrm{~mL}$ was quickly aspirated from both nostrils with two olives and a Y-piece connected to a $25 \mathrm{~mL}$ syringe. The median of three measurements at each time was used.

\section{Statistics}

Nonparametric statistics were used. For the analysis of repeated measurements Friedman's analysis of variance (ANOVA) was used and, when significant, was followed by the Wilcoxon signed-rank test for matched pairs. The Bonferroni correction was used for multiple comparisons. A p-value $<0.05$ was considered significant. Analyses and figures were made using Statistica. Data are presented as mean \pm SEM.

\section{Results}

\section{Tracheotomized patients}

In the tracheotomized patients NO levels, exhaled from the trachea, mouth and nose, respectively, at a flow rate of $0.05 \mathrm{~L} \cdot \mathrm{s}^{-1}$ (FENO,0.05), were $5.9 \pm 1.3,14 \pm 4$ and $56 \pm 9 \mathrm{ppb}$. Corresponding $V$ NO were $18 \pm 4,40 \pm 11$ and $157 \pm 25 \mathrm{~nL} \cdot \mathrm{min}^{-1}$, respectively. Oral values were significantly higher than tracheal values $(\mathrm{p}=0.014)$ and nasal values exceeded the oral values $(\mathrm{p}=0.010$, fig. 1$)$.

There was a statistically significant difference in inhaled NO concentration (FINO,0.2) when comparing nasal inhalation $(64 \pm 14 \mathrm{ppb})$ to oral inhalation

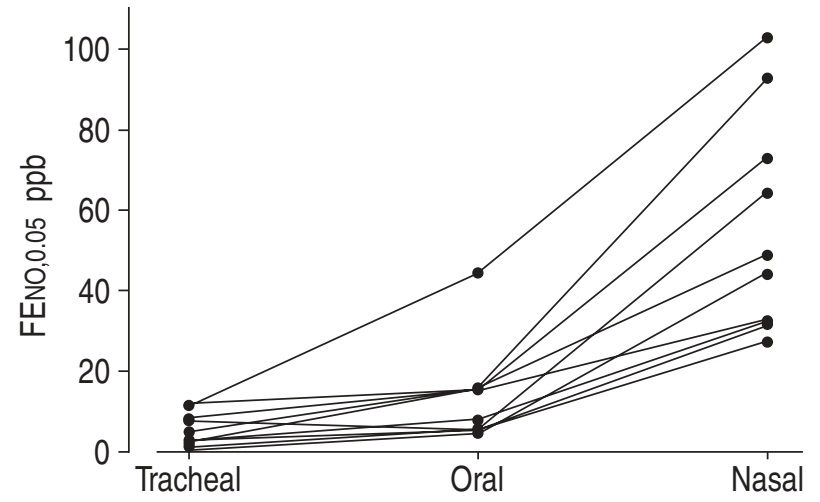

Fig. 1.-Fraction of nitric oxide during a single-breath exhalation at a flow of $0.05 \mathrm{~L} \cdot \mathrm{s}^{-1}(\mathrm{FENO}, 0.05)$ in 10 tracheotomized patients. Mean \pm SEM FENO, 0.05 were $5.9 \pm 1.3,14 \pm 4$ and $56 \pm 9$ parts per billion (ppb), from the trachea, mouth and nose, respectively. Oral values were significantly higher compared to the tracheal values $(\mathrm{p}=0.014)$ and nasal values were higher than the oral values $(\mathrm{p}=0.010)$.

(11 $\pm 3 \mathrm{ppb}, \mathrm{p}=0.03$, fig. 2). Regarding tracheal inhalation, the level was $4 \pm 1 \mathrm{ppb}$. Corresponding $V$ NO was $47 \pm 15,150 \pm 62$ and $854 \pm 203 \mathrm{~nL} \cdot \mathrm{min}^{-1}$ for tracheal, oral and nasal inhalation, respectively.

When the tracheotomized patients performed tidal breathing NO peak concentrations were $3 \pm 0.7 \mathrm{ppb}$ during tracheal, $7 \pm 2$ ppb during oral and $35 \pm 9$ during nasal breathing. A significant difference was seen between tracheal and oral breathing $(p=0.033)$ and between oral and nasal breathing $(\mathrm{p}=0.010)$.

\section{Healthy subjects}

Nasal FENO in the healthy subjects was $74 \pm 14$, $44 \pm 10,26 \pm 6$ and $19 \pm 4 \mathrm{ppb}$ at flow rates of $0.05,0.1$, 0.2 and $0.3 \mathrm{~L} \cdot \mathrm{s}^{-1}$, respectively. Corresponding $V \mathrm{NO}$ increased progressively with higher flow rates (fig. 3). FINO was $93 \pm 17,65 \pm 12,49 \pm 6$ and $51 \pm 9$. Inspiratory $V$ NO also increased at higher flows and, to a large extent, compared to exhalation. $V$ NO was significantly

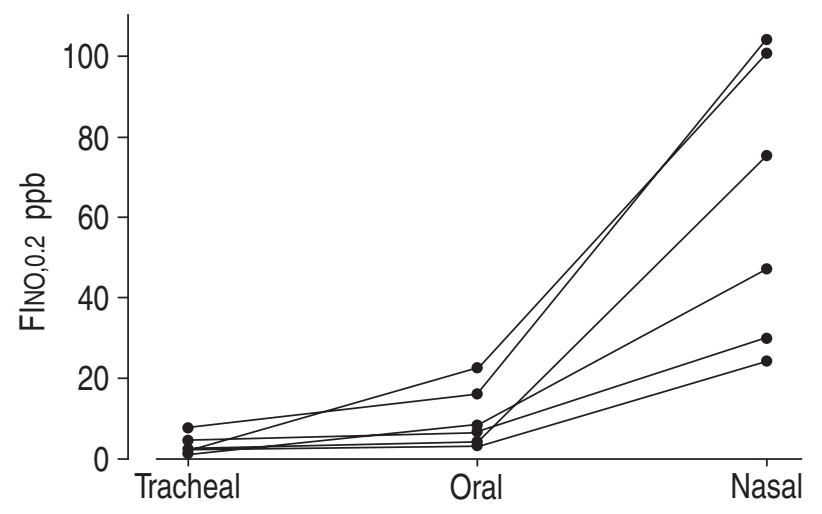

Fig. 2.-Intratracheal concentrations of nitric during inhalation at a flow of $0.2 \mathrm{~L} \cdot \mathrm{s}^{-1}($ FINO,0.2) in six tracheotomized patients. Mean \pm SEM FINO, 0.2 were $4 \pm 1,11 \pm 3$ and $64 \pm 14$ parts per billion (ppb) for tracheal, oral and nasal inhalation, respectively. There was a statistically significant difference when comparing nasal inhalation with oral inhalation $(\mathrm{p}=0.03)$. 


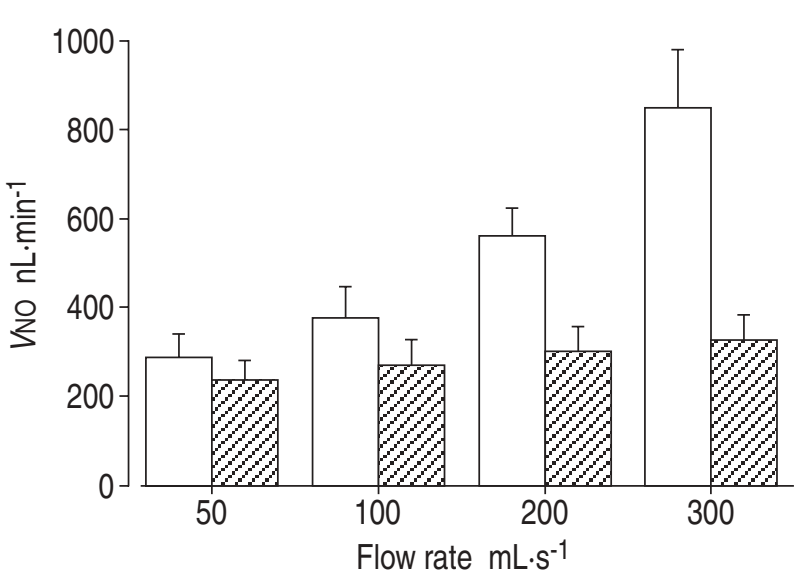

Fig. 3.-Mean nitric oxide output $(V \mathrm{NO})$ at different flow rates in seven healthy subjects performing single-breath nasal inhalation $(\square)$ and nasal exhalation $(\mathbb{Z})$. V NO was significantly higher during inspiration than expiration for flows of 200 and $300 \mathrm{~mL} \cdot \mathrm{s}^{-1}$ ( $\mathrm{p}=0.028$ and $\mathrm{p}=0.018$, respectively).

higher during inspiration than expiration for flows of 0.2 and $0.3 \mathrm{~L} \cdot \mathrm{s}^{-1}(\mathrm{p}=0.028$ and $\mathrm{p}=0.018$, respectively). There was no statistically significant difference in $V \mathrm{NO}$ for 0.05 and $0.1 \mathrm{~L} \cdot \mathrm{s}^{-1}(\mathrm{p}=0.24)$.

Nasal bolus aspiration after $0,1,2$ and $3 \mathrm{~s}$ showed NO levels of $93 \pm 15,175 \pm 18,222 \pm 25$ and $281 \pm 25 \mathrm{ppb}$, respectively (fig. 4). A statistically significant increase between each time step was noted up to $2 \mathrm{~s}(\mathrm{p}=0.036)$, but no significant change was observed between 2-3 s $(\mathrm{p}=0.056)$.

\section{Discussion}

In the present study a substantial contribution of nasally- and orally-produced NO during both inhalation and exhalation was found. There was a marked flow dependency of nasal NO output, with the highest levels observed during inhalation at flows similar to those seen during normal breathing. Nasal cavity air

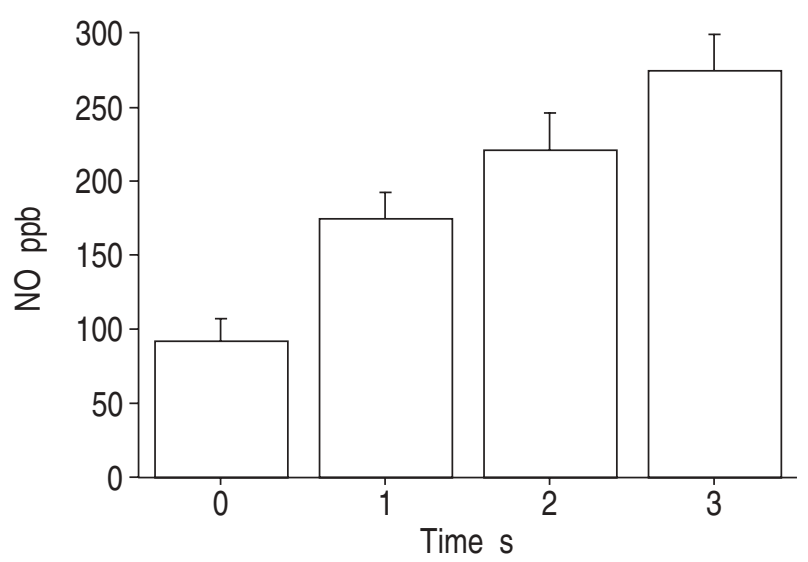

Fig. 4.-Mean nasal nitric oxide (NO) concentration in seven healthy subjects after a breath-hold of $0,1,2$ and $3 \mathrm{~s}$. Twentyfive millilitres of nasal gas was aspirated. A statistically significant increase between each time step was noted up to $2 \mathrm{~s}(\mathrm{p}=$ $0.036)$ but the change between $2-3 \mathrm{~s}$ was not significant $(\mathrm{p}=0.056)$. ppb: parts per billion. at end-expiration contained high levels of NO, which, during the following inhalation, may have effects upon gas exchange and pulmonary vascular tone. During exhalation, the oral cavity contributes by more than half to the levels of NO in orally-exhaled breath, which must be considered when evaluating data in studies using exhaled NO.

\section{Exhaled nitric oxide}

The authors were surprised to find that less than half of the amount of NO originated in the lower airways when exhaled NO was measured in a standardized manner. The present data show the oral contribution to be substantial. ZeTTERQuist et al. [6] showed an increase in orally-exhaled air upon nitrate ingestion. Other investigators have proposed that orally-exhaled air reflects NO levels from the lower airways [19, 20]. DwEIK et al. [20] found that mouth measures of NO accurately reflected lower airway levels. However, in that study tidal breathing was performed without concomitant flow measurements, making it hard to interpret these data. Because the oral contribution to exhaled NO may be dependent on nitrate intake, which is abundant in, for example, green leafy vegetables, diet can affect evaluations of exhaled NO when used as a marker of inflammation in the lower airways [21]. It is established that exhaled NO is increased in asthma [2, 4] and that this increase is due to an upregulation of NO production in the lower airways [22, 23]. In normal subjects a mouthwash procedure reduces exhaled NO [6]. In another study, a similar absolute decrease in exhaled NO was shown in asthmatics and normal subjects after mouthwash. However, the relative reduction was much larger in the normal subjects [24]. This suggests that the oral component is not responsible for the increase in exhaled NO seen in asthmatics. However, knowledge and perhaps control of food intake may be necessary to more precisely evaluate exhaled NO. The exact origin of the oral NO contribution is not known. Apart from oral bacteria, mainly situated at the base of the tongue, it is possible that structures in the upper part of the trachea or in the oropharynx could contribute by means of NOS activity in these regions.

Nasal exhalation output was four- and nine-times higher than oral and tracheal exhalations, respectively. Hence, only $10 \%$ of nasally-exhaled NO is derived from the lower airways. Since the first description of nasal NO by Alving et al. [4] in 1993, several investigators have confirmed that the nasal airways are a major source of NO [25, 26]. In the paranasal sinuses a high continuous production occurs, which contributes to the NO levels in the nasal airways [27]. With regard to orally-exhaled NO, mainly used for the investigation of lower airway inflammation, the nasal NO production is considered to be a contamination problem. Therefore, exhalation against a resistance, closing the soft palate, was used to avoid this contamination [26, 28]. Other methods for evaluating nasal NO production have been suggested [7], but to date there is no clear-cut consensus regarding which method is the most appropriate. 
However, measurements of nasal NO may provide information about pathology in the upper airways, such as in rhinitis and sinusitis, and in ciliarydysfunction syndromes.

In accordance with earlier studies, tracheal FENO,0.05 was low. Using flexible fibreoptic bronchoscopy, Kimberly et al. [26] reported higher NO levels in the nasopharynx than intratracheally, where mean NO was $18 \mathrm{ppb}$. A study by DweIK et al. [20] concluded that a larger concentration of NO reached the trachea when breathing nasally compared to orally. However, flow was not measured in that study.

A direct comparison with these and other studies is impossible since, to the best of the authors' knowledge, NO exhaled directly from the lower airways has not previously been studied and compared using a standardized technique.

\section{Inhaled nitric oxide}

In this study it has been shown that nasal inhalation generates a six-times higher FINO,0.2 than oral inhalation, with absolute values $\sim 60-70 \mathrm{ppb}$. Hospital compressed air is often contaminated with NO, which effects patients. Levels of $13-79 \mathrm{ppb}$ and 2-550 ppb improve oxygenation in neonates [29] and adults [30], respectively. In a study by MourGEON et al. [15], it was shown that more than half of the maximal effect of inhaled exogenous NO on arterial oxygenation and pulmonary artery pressure in patients with ARDS was achieved at levels of $150 \mathrm{ppb}$. Thus, the levels of nasally-inhaled NO found in the present study may be sufficient to improve oxygenation in a physiological manner. Additional effects of autoinhaled endogenous NO may occur: it has known bacteriostatic effects, improves respiratory ciliary beat frequency, inhibits platelet aggregation and may act as a radical scavenger, especially at low concentrations.

The nasal-bolus experiments were carried out in order to estimate the concentration of the initial bolus of NO that may reach the lungs during nasal inhalation. This portion $(25-50 \mathrm{~mL})$ naturally contains higher NO levels, whereas the remaining portion of inhaled air has levels of NO as described earlier. KatAYAMA et al. [31] showed that the addition of small initial boluses of exogenous NO to inhaled air reduced pulmonary vascular resistance in patients with pulmonary hypertension. Therefore, it is reasonable to believe that the nasal-cavity air bolus of relatively high levels of NO reaches the alveoli and, consequently, the adjacent vasculature, where it may be important in modulating pulmonary function.

One of the aims of this study was to compare exhaled and inhaled nasal levels of NO at the same flow. However, the tracheotomized patients where unable to perform inhalations, at a flow rate of $0.05 \mathrm{~L} \cdot \mathrm{s}^{-1}$, long enough to reach a plateau. This was more easily achieved by the healthy subjects. They were also able to exhale and inhale through the nose at different flow rates; $0.05 \mathrm{~L} \cdot \mathrm{s}^{-1}$ was chosen for comparison with exhaled NO (the ATS standard flow for exhaled NO) as were $0.1,0.2$ and $0.3 \mathrm{~L} \cdot \mathrm{s}^{-1}$ since some of the patients deviated $0.1 \mathrm{~L} \cdot \mathrm{s}^{-1}$ from the target flow of $0.2 \mathrm{~L} \cdot \mathrm{s}^{-1}$.

The finding of a flow-dependent nitric-oxide output from the nose is in line with previous studies [16, 32]. This may be explained by an increased gradient of nitric oxide from the nasal mucosa to the lumen when the luminal concentration is lowered by the increased flow. Furthermore, increased flow induced somewhat of a shift from laminar flow to more turbulent flow, which may harvest more nitric oxide from the nasal mucosa [33]. Another explanation is based on the findings of LundBERG et al. [27], who showed high nitric oxide levels in the paranasal sinuses. The air in the sinuses is constantly exchanged depending on several factors, such as the size of the ostia and the shape of the nasal cavity and nasal air flow [34]. With increased flow there is a greater exchange of sinus air. Unpublished observations from the authors' group have shown that the pressure in the maxillary sinus drops during inhalation but increases during exhalation, indicating airflow from the sinuses during inhalation and the opposite during exhalation. The anatomy of the nasal airways and conchae might create aerodynamic effects favouring sinus air donation during inhalation. The difference in flow dependency of nitric-oxide output from the nose between inhalation and exhalation was most evident at flow rates similar to those found during normal breathing. This may further support the possibility that upper airway nitric oxide has a physiological role as an airborne mediator in the airways.

Acknowledgements. The authors would like to thank R. Woodhouse for expert advice and support.

\section{References}

1. Gustafsson LE, Leone AM, Persson MG, Wiklund NP, Moncada S. Endogenous nitric oxide is present in the exhaled air of rabbits, guinea pigs and humans. Biochem Biophys Res Commun 1991; 181: 852-857.

2. Kharitonov SA, Yates D, Robbins RA, LoganSinclair R, Shinebourne EA, Barnes PJ. Increased nitric oxide in exhaled air of asthmatic patients. Lancet 1994; 343: 133-135.

3. Lundberg JO, Rinder J, Weitzberg E, Lundberg JM, Alving K. Nasally exhaled nitric oxide in humans originates mainly in the paranasal sinuses. Acta Physiol Scand 1994; 152: 431-432.

4. Alving K, Weitzberg E, Lundberg JM. Increased amount of nitric oxide in exhaled air of asthmatics. Eur Respir J 1993; 6: 1368-1370.

5. Lundberg JO, Weitzberg E, Nordvall SL, Kuylenstierna R, Lundberg JM, Alving K. Primarily nasal origin of exhaled nitric oxide and absence in Kartagener's syndrome. Eur Respir J 1994; 7: 1501-1504.

6. Zetterquist W, Pedroletti C, Lundberg JO, Alving K. Salivary contribution to exhaled nitric oxide. Eur Respir J 1999; 13: 327-333.

7. Recommendations for standardized procedures for the on-line and off-line measurement of exhaled lower respiratory nitric oxide and nasal nitric oxide in adults 
and children-1999. This official statement of the American Thoracic Society was adopted by the ATS Board of Directors, July 1999. Am J Respir Crit Care Med 1999; 160: 2104-2117.

8. Frostell C, Fratacci MD, Wain JC, Jones R, Zapol WM. Inhaled nitric oxide. A selective pulmonary vasodilator reversing hypoxic pulmonary vasoconstriction. Circulation 1991; 83: 2038-2047.

9. Weitzberg E, Rudehill A, Alving K, Lundberg JM. Nitric oxide inhalation selectively attenuates pulmonary hypertension and arterial hypoxia in porcine endotoxin shock. Acta Physiol Scand 1991; 143: 451452.

10. Pepke-Zaba J, Higenbottam TW, Dinh-Xuan AT, Stone D, Wallwork J. Inhaled nitric oxide as a cause of selective pulmonary vasodilatation in pulmonary hypertension. Lancet 1991; 338: 1173-1174.

11. Kinsella JP, Neish SR, Shaffer E, Abman SH. Lowdose inhalation nitric oxide in persistent pulmonary hypertension of the newborn. Lancet 1992; 340: 819820.

12. Rossaint R, Falke KJ, Lopez F, Slama K, Pison U, Zapol WM. Inhaled nitric oxide for the adult respiratory distress syndrome. $N$ Engl J Med 1993; 328: 399-405.

13. Gerlach H, Rossaint R, Pappert D, Falke KJ. Timecourse and dose-response of nitric oxide inhalation for systemic oxygenation and pulmonary hypertension in patients with adult respiratory distress syndrome. Eur J Clin Invest 1993; 23: 499-502.

14. Lowson SM, Rich GF, McArdle PA, Jaidev J, Morris GN. The response to varying concentrations of inhaled nitric oxide in patients with acute respiratory distress syndrome. Anesth Analg 1996; 82: 574-581.

15. Mourgeon E, Puybasset L, Law-Koune JD, et al. Inhaled nitric oxide in acute respiratory distress syndrome with and without septic shock requiring norepinephrine administration: a dose-response study. Crit Care 1997; 1: 25-39.

16. Silkoff PE, Chatkin J, Qian W, et al. Nasal nitric oxide: a comparison of measurement techniques. $\mathrm{Am}$ J Rhinol 1999; 13: 169-178.

17. Gerlach H, Rossaint R, Pappert D, Knorr M, Falke KJ. Autoinhalation of nitric oxide after endogenous synthesis in nasopharynx. Lancet 1994; 343: 518-519.

18. Lundberg JO, Settergren G, Gelinder S, Lundberg JM, Alving K, Weitzberg E. Inhalation of nasally derived nitric oxide modulates pulmonary function in humans. Acta Physiol Scand 1996; 158: 343-347.

19. Kharitonov SA, Chung KF, Evans D, O'Connor BJ, Barnes PJ. Increased exhaled nitric oxide in asthma is mainly derived from the lower respiratory tract. $\mathrm{Am}$ J Respir Crit Care Med 1996; 153: 1773-1780.

20. Dweik RA, Laskowski D, Abu-Soud HM, et al. Nitric oxide synthesis in the lung. Regulation by oxygen through a kinetic mechanism. J Clin Invest 1998; 101 : 660-666.

21. Olin AC, Aldenbratt A, Ekman A, et al. Increased nitric oxide in exhaled air after intake of a nitrate-rich meal. Respir Med 2001; 95: 153-158.

22. Hamid Q, Springall DR, Riveros-Moreno V, et al. Induction of nitric oxide synthase in asthma. Lancet 1993; 342: 1510-1513.

23. Massaro AF, Mehta S, Lilly CM, Kobzik L, Reilly JJ, Drazen JM. Elevated nitric oxide concentrations in isolated lower airway gas of asthmatic subjects. Am J Respir Crit Care Med 1996; 153: 1510-1514.

24. Storm van's Gravesande JM, Heinzberger C, Alving K, Moseler M, Kuerhr J. Effect of mouthwash with sodium bicarbonate before measurements of exhaled nitric oxide in children. Eur Respir J 1999; 14: Suppl. $30,441 \mathrm{~s}$.

25. Schedin U, Frostell C, Persson MG, Jakobsson J, Andersson G, Gustafsson LE. Contribution from upper and lower airways to exhaled endogenous nitric oxide in humans. Acta Anaesthesiol Scand 1995; 39: 327-332.

26. Kimberly B, Nejadnik B, Giraud GD, Holden WE. Nasal contribution to exhaled nitric oxide at rest and during breathholding in humans. Am J Respir Crit Care Med 1996; 153: 829-836.

27. Lundberg JON, Farkas-Szallasi T, Weitzberg E, et al. High nitric oxide production in human paranasal sinuses. Nature Med 1995; 1: 370-373.

28. Silkoff PE, McClean PA, Slutsky AS, et al. Marked flow-dependence of exhaled nitric oxide using a new technique to exclude nasal nitric oxide. Am J Respir Crit Care Med 1997; 155: 260-267.

29. Lum LC, Tan PS, Saville A, Venkataraman ST, Pinsky MR. Occult nitric oxide inhalation improves oxygenation in mechanically ventilated children. J Pediatr 1998; 133: 613-616.

30. Lee KH, Tan PS, Rico P, Delgado E, Kellum JA, Pinsky MR. Low levels of nitric oxide as contaminant in hospital compressed air: physiologic significance? Crit Care Med 1997; 25: 1143-1146.

31. Katayama Y, Higenbottam TW, Cremona G, et al. Minimizing the inhaled dose of NO with breath-bybreath delivery of spikes of concentrated gas. Circulation 1998; 98: 2429-2432.

32. Dubois A, Douglas J, Stitt J, Mohsenin V. Production and absorbtion of nitric oxide in the nose. $J$ Appl Physiol 1998; 84: 1217-1224.

33. Djupesland PG, Chatkin JM, Qian W, et al. Aerodynamic influences on nasal nitric oxide output measurements. Acta Otolaryngol 1999; 119: 479-485.

34. Aust R, Drettner B. The functional size of the human maxillary ostium in vivo. Acta Otolaryngol 1974; 78 : $432-435$. 